\title{
Saber ver el paisaje ${ }^{1}$ Understanding the landscape
}

\author{
Eduardo Martínez de Pisón*
}

INTRODUCCIÓN

«Les grandes personnes ne comprennent jamais rien toutes seules, et c'est fatigant, pour les enfants, de toujours leur donner des explications».

(A. de Saint-Exupéry, Le Petit Prince)

Hubo un libro de un profesor de la universidad de Pisa, Matteo Marangoni, que tuvo éxito desde los años cuarenta a los sesenta entre los aprendices españoles de estética e historia del arte, que ciertamente no eran muchos. Se titulaba Saper vedere, y en su edición española Para saber ver. (Cómo se mira una obra de arte) (Marangoni, 1951). Al pensar en el uso y el desuso del concepto geográfico de «paisaje» he recordado repetidas veces la misma necesidad que dio pie a escribir aquella obra aplicable a nuestro caso: aprender a ver el paisaje, saber verlo. Escribía Marangoni que es preciso ver el arte pictórico, el arquitectónico o el escultórico para conocerlos y sentirlos, aunque algunos acusasen de formalistas a quienes lo propugnaban. Y, por ello, que era necesario «crear una aptitud para la contemplación». Podríamos trasladar el argumento a la geografía.

\footnotetext{
${ }^{1}$ Este trabajo se ha realizado dentro del Proyecto de Investigación CSO2008-03877, financiado por el Ministerio de Ciencia e Innovación y el FEDER.

* Facultad de Filosofía y Letras, Universidad Autónoma de Madrid (eduardo.martinez@uam.es).
} 
Al intentar dar utilidad a este escrito, he creído oportuno centrarlo sobre esta aptitud, la de saber ver el paisaje, en el campo de nuestro trabajo habitual. Lo hago en forma de ensayo, como era la manera de exposición referida al arte que da pie a la aplicación de aquel título y aquella idea a este artículo. Lógicamente, saber ver el paisaje debería ser previo a saber estudiarlo. De este modo, parece razonable pensar que conviene empezar la reflexión por el mismo principio. Pero he de advertir que, cuando digo utilidad, me refiero, claro está, al sentido del estudio geográfico, no - como pudiera entenderse- para aplicarla a la práctica de la exhibición curricular, tan extendida por ser obligatoria, aunque a veces su mecanismo parezca más propio de la hostería de Buttarelli que de la función universitaria.

\section{CÓMO SE MIRA UN PAISAJE}

Ordenando un día papeles de fines también de los años cincuenta encontré un cuaderno con notas mías de viaje en las que aparecía la influencia que las clases de un profesor de geografía, Manuel de Terán, habían ejercido ya en uno de sus alumnos. Son, en parte, apuntes tomados en una excursión al Campo de Criptana, con pretensión geográfica, simples observaciones de lo prendido con la vista desde un otero, pero con una mirada y un prurito de orden despertados por su modo de explicarnos el mundo. Los completaba con la ilustración a lápiz de un molino, un plano de su planta, una rosa de los vientos con sus nombres molineros (cierzo, matacabras, solano alto, solano fijo y solano hondo, mediodía, ábrego, toledano y moricote), un inventario con croquis de los elementos de su maquinaria y de la armadura del tejado de la casa del molinero, con el nombre de todos sus maderos: solera, talón, hilera, lazo, par, jabalcón, correa, ejión, cabrio, tornapunta, tirante, péndula y pendolón. Páginas después hay otro pequeño catálogo de topónimos con sus significados, tomados en una excursión hace medio siglo por una comarca asturiana, para reconstruir un mapa del paisaje evocado: artedo (de zarzas), fenosa (de heno), orderías (de cebada), centiniegas (de centeno), brañaseca (de pastos), busfrío y bustiello (de prados), biescas (de matorral), pedroso, solana, el acebo y el tejo, castañedo, faedo (de hayas), monteoscuro, y nombres de playas relacionados con la pesca costera como Cazonera (de cazón, pez voraz) o Chalanos (de barcas de poco fondo): es decir, un mapa de nombres, un mapa de funciones, un mapa de paisajes. Y, junto a él, una recolección de más de veinte elementos del hórreo (entre ellos, pilpayo, pegoyo, trabe, colondra, sobigaño, durmiente, subidera, etc.). Este ejemplo no constituye sino una pre- 
tensión concreta, en versión ingenua, de inicio en un estilo de una geografía entonces explícita y sugerente, atenta a lo natural, rural, urbano, cultural, etnográfico - la referencia a una conocida disertación de Caro Baroja sobre los molinos de viento era entonces reciente-, histórico, estructural, descriptivo y explicativo, con el atractivo de su sagacidad de espíritu, método, observación de campo y archivo, y sentido de reunión de rasgos en el paisaje. De lo que no se encontraba sólo en los libros, sino en la realidad territorial. En ello estábamos los geógrafos, incluso aprendices, con naturalidad. Por supuesto, hace tiempo que aquel molino no muele; sólo su silueta resiste aún sobre el cerro. Tampoco han aguantado orderías, fenosas, casas y hórreos. Pero ¿ha dejado entretanto de ser interesante entender sus historias y sus cambios en continuidad con aquel estilo de mirada?

Encuentro huellas atractivas de ese modo de ver las cosas tanto dentro como fuera de la geografía. No hace mucho, relativamente, en 2004, llegó a mis manos un trabajo de arquitectura que aún guarda una herencia o extensión de aquel tono, propagado provechosamente fuera de la geografía. Se titula de modo expresivo El paisaje como archivo del territorio, del que es autora Esther I. Prada (2004). Han pasado algunas generaciones, pero el paisaje agrario sigue siendo aquí una clave formal de mostrarse tal reunión configurada. Aunque no sólo evolucionan los métodos de los observadores, sino los paisajes observados. Detrás están, sin embargo, explícitamente «la vida y el trabajo» acumulados en el tiempo sobre el espacio, la «comunidad y experiencia», la organización de lo público y lo privado, que se decantan a modo de imagen, hoy progresivamente debilitada. El paisaje es su producto y es su revelación. El dibujo rescata por parte del investigador, en el proceso de reconocer, interpretar y exponer, las morfologías históricas de terrazgos y asentamientos. Como antaño el geógrafo, el arquitecto recupera los trazos naturales y culturales del paisaje (de la llanura o la ribera a la casa de labranza, los puentes, muros, abrevaderos, núcleos, cortinas, faceras, montes, dehesas) y las viejas palabras que lo definían. Y la recuperación de esos términos trae consigo los significados de un medio y una actividad: aricar, cortino, derrota, heredad, barzón, bielda, mancera, cernidero. Esto me hace pensar que la perspectiva del geógrafo sigue siendo fértil tanto dentro como fuera de casa.

Hay que tener en cuenta que, como es sabido, los paisajes propiamente terrestres son un hecho insólito en el Cosmos próximo, una excepción en el sistema solar, sobre todo por su componente vital y por su referencia antrópica, atributos de los que los demás, astro, planetas, satélites y ocasionales meteoritos, carecen. En la Tierra sólo son relativamente asociables a lo cósmico como paisajes los desiertos, las zonas polares, los volcanes y la alta montaña. Es una 
constatación obvia, pero que se hace como muestra de la perspectiva de un geógrafo físico. Lo demás es propio, o bien mezcla o, con frecuencia, dominios de agua, de vida, como campos, bosques o ciudades. El estudio de tales paisajes es, por tanto, específico de la geografía por su mismo prefijo, sin que eso quiera decir que los demás lugares se excluyan, pues son naturaleza terrestre, tan terrestres como Manhattan. El paso normal futuro (y no lejano) de la geografía a la uranología ensanchará obligatoriamente el inventario profesional de objetos y, con él, el número de musas que nos asisten, pero por ahora nos atenemos a lo terreno y, en esto, concedemos el énfasis correcto a sus paisajes más exclusivos. Decían unos versos de Manuel Alcántara que «el mar se quedará navegando / aunque no haya nadie aquí». Pero el significado del paisaje será distinto, si es que queda alguno, por lo que preferiría oponerle de momento la sencilla alegoría de Lope de Vega: «Digan los pastores, / respondan las sierras».

Así recomendaba el maestro Deffontaines a sus discípulos viajeros en 1980: «D'abord regarder le paysage qui forme le cadre dans lequel s'est organisée toute la vie d'un groupe humain: plaine cultivée, forêt ou montagne, vallée». El geógrafo francés argumentaba la conveniencia de caminar en zigzag para observar todas las texturas, las mezclas y los límites del paisaje, recoger sus nombres, dibujar sus rasgos, cartografiarlos: «en un mot, sentir le pays» (Deffontaines, 1980). También extrañaba a Bacon en 1625 que «en los viajes marítimos, donde no hay nada que ver sino cielo y mar, los hombres escriban diarios; pero en los viajes por tierra, donde hay tanto que observar, la mayoría no los escriben», y proponía por ello abrir los ojos a los puertos, a las ruinas, a las bibliotecas, a las casas y jardines, a las ciudades y cosas memorables (Bacon, 1961). Porque la geografía aprendida —añadía — es la educación de la juventud y la experiencia de la vejez.

La geografía no ha ido ni es cosa menor. Somos geógrafos en un entorno intelectual y en un estado del territorio en los que toma sentido nuestra aportación. La geografía tiene solicitaciones diversas, que van para mí desde el rigor de un oficio que busca representar el mundo hasta la emoción de la exploración y el viaje. Digo esto último porque la geografía se ha movido en tales coordenadas, entre los mundos conocidos y los desconocidos, siendo una de sus obligaciones y placeres la extensión de ese conocimiento, con ejemplos tan brillantes como el salto histórico a América, el asalto a los confines hasta los mismos polos ya en el siglo xx o la conquista de las montañas, primero domésticas y luego remotas, es decir, los últimos paisajes sublimes. La geografía ha seguido sus tiempos y sus indicaciones culturales, con frecuencia en la excelencia de tales tiempos. La geografía se ha hecho con escue- 
las sólidas de pensamiento, con muestras de posición ante el mundo y, por tanto, con ética respecto al Cosmos: y por eso, para Kant, la geografía debería ser entendida como el sustrato espacial del conocimiento (Unwin, 1992).

Pero representar bien este papel no es cosa fácil ni poco trabajosa. Podría aplicar a tal exigencia aquello que J. P. Forner escribía en 1782, refiriéndose a la buena poesía, en sus Exequias de la Lengua Castellana: «Había yo oído muchas veces en mi niñez que el viaje al Parnaso era empresa ardua y difícil, así por lo estrecho y áspero del camino, como por lo escarpado e inaccesible de la cumbre» (Forner, s. a.). Como todo saber y toda ciencia, si la geografía quiere estar a la altura de las circunstancias que le planteó Kant, y debería tenerlo como diana, no le queda más remedio que emprender su ascenso al Parnaso de la actual cultura con un objetivo, un método y un bagaje propios. Tiene varios caminos definidos, pero uno, indudablemente, es el del paisaje. La geografía tiene expresa en sus raíces la idea de paisaje y la de respeto al paisaje, que puede renovar hoy, cuando más falta hacen ambas modalidades. Y, como en los versos de Jacques Prévert, ocurrirá que « une plume ou un crayon courant sur le papier / raconte le paysage / et le paysage prête l'oreille / parce que le voyageur lui plaît / et il écoute le langage / qui le décrit trait por trait » (Prévert, 1955). En cualquier caso, si se quiere, puede ser una bella y oportuna misión.

Pero hay que definir qué se quiere hacer. Los acercamientos posibles tienen muchos lados: historia de un concepto y de un objeto de trabajo, deslinde de métodos y escuelas, de etapas y obras, políticas y prácticas de la protección de los paisajes, aplicación diversa de esas políticas y prácticas, cultura territorial y unidades de paisaje en montañas, bosques, montes, ríos, lagos, humedales, costas, ámbitos rurales y urbanos, jardines y monumentos, conjuntos y asociaciones en esferas regionales, experiencias, paisajes identitarios y de memoria, valores, y, claro está, inventarios, identificaciones, clasificaciones, cartografía. También intervención experta. El trabajo geográfico sobre el paisaje está compuesto por análisis de su estructura, su dinámica, su territorialidad, sus funciones, sus componentes, su historia, sus unidades, sus formas, sus rostros y sus contenidos culturales. Y bastante más. Pero conjugando la entrada en el lienzo de detalle con no caer en disociar lo asociado, de modo que se procure ofrecer la geografía como un entretejido de componentes y lugares. En tiempos reductivistas no parece un propósito a favor de corriente, pero precisamente por eso hay que indicarlo. Tampoco estimo deseable, claro está, una geografía de contenido difuso como el salón de los espejos donde no se acierta a distinguir los objetos y sus reflejos. Me permito añadir, con leve humor, que no se debería llegar a que pueda aplicársele, ya 
sea como consecuencia de nuestra irreflexión, pragmatismo o busca de aura popularis, aquello tan conocido de una canción costumbrista: «hace tiempo que vengo al taller y no sé a qué vengo». Aunque todo puede pasar.

Porque este es el verdadero reto del método. La integración sigue siendo un objetivo metodológico. Para acercarnos más al paisaje real como textura es necesario primar los aspectos de relación y de conjunto, ir más allá de lo que se ha conseguido, sin renunciar a los logros en lo parcial. El siguiente paso será, si hay persistencia en tales estudios, aparte de no cejar en el puesto intelectual que les corresponde dentro y fuera de la geografía, tratarlos como composición configurada y como unidad dinámica. Referirse al conjunto y formalizar métodos específicos de integración. Abrirse a lo nuevo, sumar componentes y significados, por una parte, agregar lo que faltaba, y, por otra, cerrar el círculo del conjunto asociado como tal decantación. Por ejemplo, sabiendo ver en el paisaje incluso lo que no se ve en él y sin embargo lo constituye. Y además, realizando la exposición o representación geográfica mediante las siguientes pautas: primero, caracterización de la composición completa del paisaje; segundo, análisis de factores, componentes y partes; tercero, reunión de elementos constituyentes; cuarto, retorno a la escala inicial de conjunto con la conclusión de las texturas y dinámicas de dicho conjunto. A veces no es fácil evitar perderse en lo excesivo, en los dos infinitos pascalianos de lo grande y lo pequeño, lo infinitamente ampliable y lo infinitamente divisible: el paisaje es quizá una regla entre la extrema distancia y la demasiada proximidad al objeto. Para no entrar en esquematismos, viene a cuento aquella recomendación de Juan Ramón Jiménez: si te dan papel rayado, escribe en otro lugar. Es, pues, un reto al talento más que a las recetas. Decían los griegos y latinos que los hombres de talento se suelen volver melancólicos: es el único riesgo.

El paisaje del geógrafo tiene un contenido y es un modo de mirar desde ese significado, una construcción intelectual, una imagen del lugar con representación ajustada (pues sin lugar no hay paisaje preciso). Es una concepción del mundo, un sentido de la Tierra fundado en valores mayores. Es una atención al mundo real identificado y valorado, más allá de la superficie del cambio territorial que avanza por sus propios mecanismos, incluso es una reacción cultural frente a tales mecanismos. El paisaje está fundado en la asociación espacial de sus fuerzas y componentes, es el escenario, es su génesis y tendencias y es las calidades que resultan de su lectura. La huella del hombre en la Tierra que lo acoge es paisaje a través de la historia, es referencia profunda y reflexión en sus vaivenes, no es una configuración vacía sino animada. Cuando decimos que hay paisajes ordenados y desordenados parecemos dar 
por supuesto que hay o debe haber un orden tácito en ellos. Pese a que los paisajes son complejos geográficos organizados en individualidades situadas y significativas y no sistemas abstractos, tal constatación de posibilidad de orden en ellos es a su vez el principio de una posibilidad de ciencia, es decir, no sólo por el método de tratamiento sino por aspiración a una norma que dé razón de tal orden y estructura. Si llevamos este criterio a su extremo ideal, el paisaje podría llegar a entenderse como aquella ciudad imaginaria de Italo Calvino cuyas figuras se asemejaban a una partitura musical donde no podía cambiarse o desplazase ni una nota, pero afortunadamente la Tierra es imperfecta. En efecto, los extremos son poco interesantes: si el exceso de control regulador frena la innovación, el caos aparente sólo indica desconocimiento de la norma.

De modo habitualmente tácito, pero también explícito, para la práctica del geógrafo un territorio ha venido siendo un espacio terrestre estructurado y localizado. Y un paisaje, un territorio formalizado e interpretado. De modo que la diferencia entre espacio, territorio y paisaje existe de modo escalonado, aunque a veces es algo sutil y tal sutileza ha dado lugar a algunas confusiones conceptuales. Pero ese carácter diferenciado se establece sobre un sucesivo y necesario arraigo en el territorio y de éste en el espacio, de manera que los cambios en los espacios arrastran a los demás e incluso dan lugar a necesidades conceptuales nuevas, por ejemplo como ha ocurrido con los no-lugares, y con ello a nuevos retos intelectuales que amplían o desplazan objetivos, métodos y, cómo no, los mismos conceptos. En suma, para el geógrafo el paisaje es el territorio interpretado. Tanto es así que el concepto de paisaje, cuando lo hay, cosa que no siempre ocurre, puede llegar a encontrarse entre un unamuniano sentido de reciprocidad existencial, con su percepción como metáfora y meditación, y un análisis hegeliano de estricta racionalidad, de modo que quien mira racionalmente ve el mundo como algo racional. En cualquier caso, en este punto importa ya el paisaje con su observador añadido. Se decía antaño que la lectura de un libro penetrante, para ser efectiva, requiere un lector inteligente, o, dicho de otro modo, que, por muy buena que sea una obra, sólo se obtiene de ella lo que logra el talento de su lector: en efecto, del mismo modo, un paisaje valioso también necesita un observador cualificado. Aunque a los ingredientes de estas cualificaciones, como la adecuada preparación, ese talento y algunas cosas más, no nos podemos referir en este artículo por razones de extensión.

Para nosotros el paisaje ha sido un eje de trabajo: un asunto, un sentido, un atractivo, un objeto de investigación e incluso una escuela. Aprendimos tempranamente que los paisajes urbanos resultan de redes geográficas, vicisi- 
tudes históricas, funciones económicas, estructuras sociales, técnicas constructivas y, claro está, de las formas logradas. A un planteamiento tradicional interesado en las estructuras y formas territoriales, a veces como geosistema o como estructura agraria o como morfología urbana, etc., ha sucedido recientemente una apertura a las imágenes culturales. Se podría hacer una antología expresiva de textos de geógrafos españoles sobre el paisaje, por ejemplo -entre otros igualmente conocidos- con hitos de Terán en teoría, de paisajes agrarios con García Fernández, de cultura con Ortega Cantero, de aplicación con Nogué, etc. Hoy parece que estamos ante un viento favorable a la recuperación, la extensión y la diversificación del concepto de paisaje, incluso con pasos desde lo académico y romántico a lo técnico y pragmático. Sin duda hay otras tradiciones extrageográficas sobre el objeto, la idea y la representación del paisaje, pero además hay hoy emersiones sobre este asunto, internas y externas, que requieren actualizaciones. Entre las tradiciones podemos señalar las culturales, claramente en literatura y pintura, a veces en filosofía, y las técnicas, como en jardinería paisajista, con conciencia en Europa de este calificativo desde el siglo XIX. Y entre las emersiones asistimos a surgimientos en materias tan variadas como las técnicas (arquitectura, ingeniería, paisajismo), científicas (psicología, ecología), empresariales, mediáticas, jurídicas, preservacionistas, administrativas y políticas. Naturalmente también hay abundantes áreas oscuras del paisaje, en general su invisibilidad para un extenso modo de entender el territorio, y, en aquellos que lo llegan a entrever, habitualmente como un bien menor de interés subordinado a la ordenación productiva del espacio geográfico. No obstante, la geografía es la perspectiva por excelencia para ver el paisaje. De manera que ver el paisaje geográficamente suma la racionalidad del objeto a la del método e incluye su interpretación cultural.

No es innecesario decir que para el geógrafo el mundo exterior existe, porque, por ejemplo, para el poeta eso no está tan claro. Pessoa escribía que en arte importa más la expresión que lo expresado, lo que se siente sobre las cosas que lo que esas cosas son. Soportaba menos los males de la inteligencia que los de los sentimientos. Los paisajes eran para él más símbolos que paisajes, ecos de lo real, por lo que concluía categóricamente: «no creo en el paisaje» (Pessoa, 1996). Hay sólo el individuo, con la ventana cerrada, y al otro lado el mundo, y acaso un sueño del paisaje que no es el paisaje. $\mathrm{O}$, en todo caso, una intersección de un paisaje y un sueño. De todos modos los poetas son tan necesarios como contradictorios. Iluminan los paisajes a la vez que los niegan. Así son, para compensar, vivificantes, aplicados al paisaje, estos versos de Victor Hugo, escritos en 1856: «Tout, comme toi, gémit, ou chante comme 
moi ; / tout parle. Et maintenant, homme, sais-tu pourquoi / tout parle ? Écoute bien. C'est que vents, ondes, flammes, arbres, roseaux, rochers, tout vit ! / Tout est plein d'âmes » (Hugo, s.a.).

\section{EL PAISAJE COMO MARCO Y EXPERIENCIA}

No sólo el marco encuadra el paisaje, sino que el paisaje me rodea como mi marco, pues en el paisaje se nace, vive y muere. Este marco es también medio, es circunstancia, es referencia y pensamiento. El paisaje nos nutre física y espiritualmente. Por ejemplo, es belleza y es frío, casa e intemperie, es mío y es otro. Hay paisajes que nos esperan y algunos que nos dejan en el camino. Tienen sus normas, tiempos, ritmos a los que pertenecemos más o menos sumisamente. Hay paisajes que imponen y paisajes a los que nos imponemos, paisajes sin espectadores y paisajes espectáculo. Paisajes de dominante cósmico, sin vida, y de caracteres vitales, con múltiples gradaciones y estilos. Paisajes históricos, incluso hasta el empacho como decía Unamuno, o sólo barridos por el viento. Hasta las naturalezas son más marcos, sustancias de la vida, que exclusivamente panoramas. En estos cuadros naturales se puede entrar, habitar, es posible quererlos, tener experiencias propias como nidos de silencio o como entes dotados de individualidad y reciprocidad.

Leí hace tiempo a alguien que dividía las culturas en dos figuras opuestas y simples, el círculo como símbolo del sosiego, que le parecía propia de oriente, y la flecha, como alegoría de la acción, característica de occidente. Y daba su solución armónica entre ambas en la espiral, el círculo abierto y dinámico. Sin duda es una imagen demasiado esquemática para meter en ella la profundidad de las culturas, pero podría aplicarse alegóricamente también a actitudes, a estados personales y, en lo que aquí tratamos, a lugares: lugares-círculo, lugares-flecha y lugares-espiral. En este terreno y tal vez en el de las personas, las flechas se están apoderando de los círculos, éstos como dianas de aquéllas. Las espirales corresponderían a los círculos dotados de solución del sosiego con una ventana abierta en su arco final por donde proyectarse, como una portilla a un cambio selectivo. Pozos o saetas son demasiado contraste, como el de los paisajes y no-paisajes, territorios cada vez más poseídos por acción, producción, mutación, ruido, y menos por permanencia, calma o melodía. El viajero ve mudar los lugares del mundo hacia menos armonía y más enervamiento. La red territorial del beneficio ya está lanzada hasta los últimos desiertos, selvas y montañas. Los confines ya están capturados. En el negocio del territorio, próximo o lejano, tal beneficio se está pagando en paisaje. Los círculos se rompen 
y los santuarios están todos asediados o asaltados. Y cuando la geografía de un lugar determinado se ha sacralizado puede que estas rupturas se sientan como profanaciones. En los espacios del sosiego y la permanencia hemos crecido como la hierba. Pero el sentimiento de tales paisajes es el de torres cercadas. El paisaje-maestro no necesita hablar, enseña en silencio, pero necesita ese silencio; en realidad, la peña inmortal que miras es quien te está mirando.

Es cierto que mi generación es especialmente reactiva al queroseno simbólico del Fahrenheit 451 de Bradbury. No sólo a la «temperatura a la que arde el papel», sino a su diagnóstico general: «el hombre del siglo xIX con sus caballos, sus carretas, sus perros: movimiento lento. Luego, el siglo xx: cámara rápida. Libros más cortos. Condensaciones [...] Se abreviaron los años de estudio, se rebajó la disciplina, se dejó de lado la historia, la filosofía y el lenguaje [...] Deportes al alcance de todos, espíritu de grupo, diversión y no hay que pensar» (Bradbury, 1965). Tal vez por eso reaccionamos con prontitud cuando aparecen condiciones en las que no sólo no se ve el paisaje, sino que estorba.

Los paisajes son los escenarios de los dramas de la realidad; no son ficción, no son telones, no son teatro. No pueden tener temporadas y cierres. Son los asentamientos de lo real, donde lo que nace nace, lo que vive vive y lo que muere muere, lo que ríe ríe y lo que sufre sufre. El paisaje es, como la cultura, como la estructura social, base de la circunstancia de la vida, el lugar de la experiencia y, por tanto, el lugar necesario. Depende de sí mismo y, cada vez más, de la experiencia que buscamos. La misma naturaleza, como paisaje, no es, así, lo otro, sino mi marco esencial y vital de referencia terrestre. Es lo que es, lo que me entrega y lo que le doy en diálogo con el mundo. Vivir así es vivir en el Tierra. ¿Puede haber un exclusivo vivir en la sociedad, sin paisaje? Tal vez, pero ya no sería vivir en la Tierra.

Hay espacios que sustituyen a los paisajes; un aeropuerto igual a cualquier otro sobre una campiña; un parque eólico cuyas dimensión y movilidad anulan el perfil leve y reposado del páramo en el que se asienta; una ciudad-plan que repite su trama y dibujo en una red impersonal y sin historia; un hotel funcional de cualquier lugar sin lugar, un hangar con nieve artificial. Todos ellos son espacios banales despersonalizados, crecientes y arrojados sobre el mundo, como si fueran paisajes o sin pretenderlo, pero sin serlo nunca, por Asia, África, Europa, América, iguales entre sí, intercomunicados por vías aéreas o autopistas o por caminos virtuales, recubridores de los paisajes reales que les sirven de solar y sustitutos de sus sistemas geográficos a pie de tierra, que anulan o vuelven ocultos sus valores o los cambian por escenarios artificiales para una sociedad del artificio que ha prescindido del paisaje. Es 
decir, no-paisajes. En cambio, donde el marco es aún el paisaje, la Tierra posee cuerpo y faz, fuera y dentro.

De modo que, más que un panorama exterior, el paisaje es un interior. En un doble sentido, primero porque es una forma que tiene su «dentro», sus paisajes internos, y segundo, porque, aunque constituida por elementos geográficos externos, se revela como paisaje por una concesión interior del hombre en un proceso de cultura, dando al territorio una categoría mayor y unas cualidades manifestadas por el conocimiento, el arte y la vivencia. El paisaje es un monumento geográfico y humilde, a todos los vientos, teñido de un agregado de conocimiento y arte. El paisaje no es sólo un panorama o un cuadro, sino que tiene interior, tantos interiores como queramos. En la montaña, por ejemplo, lo que se considera como decorado desde un mirador, si se adentra uno en él se convierte en lugar y estancia, itinerario que recorrer, desde el que se vuelve decorado el punto de vista estereotipado, desde el que se hace panorama al mirador. Esto quiere decir que, en sí misma, la rugosidad del paisaje se descompone en múltiples «dentros» y la búsqueda de tales interiores, cada vez más sublimes, es lo que ha dado lugar, en una opción cultural adecuada, a la búsqueda de la altitud, mientras ésta no sea alcanzada, claro está, por el artificio. Entonces el paisaje o no existe o es manipulado como producción territorial o no es percibido o, como mucho, no pasa de decorado.

Pero no ignoramos que la idea de paisaje más extendida es la de un panorama o la de un cuadro o una página descriptiva; o más en concreto, lo que enmarca la ventana, un encuadre, un hueco luminoso con una perspectiva y una composición definida por un marco, donde se concentra la atención. Ese es el rostro del paisaje, no el paisaje, a no ser que lo acotemos a su imagen. Incluso es una unidad de un paisaje más extenso. El paisaje está compuesto por forma, rostro e imagen. Tras el rostro hay una forma y tras la forma una estructura, ambas resultado de un proceso en el tiempo, y todo este conjunto, efecto de múltiples unidades ensambladas y enlazado a su vez con sus vecinos, integrado y zurcido por elementos correlacionados, posee además contenidos logrados por la cultura. El paisaje es ese todo de rostros, formas, sistemas, partes, tiempos, componentes y sentidos. El paisaje tiene significados. Es pues la unidad final terrestre. Y quien sabe leer paisajes recibe ese todo cada vez que arroja la mirada. El paisaje es, por tanto, un método de comprender. Por eso la relación con el paisaje es estética, es científica, es sentimental y es moral. Desde que hay cultura no hay paisajes desnudos. Un paso incluso más allá lo formulaba Goethe al decir que, una vez que el arte escogía un asunto, éste dejaba de pertenecer a la naturaleza. 
Pongamos un ejemplo simple de contraste y de enlace entre una visión territorial común y una habitual visión más paisajista de un mismo lugar campestre. Desde la primera perspectiva, probablemente sin conciencia de su encanto ni de su valor cultural, los caminos rurales se pierden porque son inútiles en la nueva estructura agraria y, si alguna vez se reabren, en forma de pistas, es para talar un monte, porque salen las cuentas de la madera, o para convertir lo que fueron prados en parcelas urbanizables, o porque sus propietarios son la clientela política de aquellos de quienes dependen los permisos locales de comunicaciones, cortas o usos del suelo como solares o plantas de energías renovables. Los argumentos justificativos más comúnmente repetidos serán, no obstante, por parte de las administraciones, que «hay que fijar población» o que prefieren aerogeneradores a centrales nucleares y, por parte de los lugareños, que ellos son los que han creado o guardado aquellos paisajes desde siempre, por lo que tienen todos los derechos a hacer con ellos lo que más les convenga. La lección era sencilla y ha sido bien aprendida. En cambio, desde la segunda perspectiva, la deseada reapertura o conservación de los caminos rurales habría de ser en su misma forma viaria, porque en ella estriba su valor, y justamente su uso consistiría en recorrer ese viejo robledo o ese umbrío castañar, amenazados ahora, que tradicionalmente atravesaban ( «je suis d'un pas rêveur le sentier solitaire », escribía Lamartine, [1963]), de modo que, quienes tienen esta mirada, dicen inevitablemente cada día su último adiós a algún paisaje. De esta manera, la aparición repentina de una excavadora en una vereda o de una fila de farolas en un descampado puede despertar con razón las alarmas del paisajista contemplativo. Lo raro es que ocurra lo contrario. En consecuencia, se suele plantear el territorio en términos de rentabilidad y el paisaje en términos de calidad. Un expresivo ejemplo reciente, de 2010, se encuentra en el planteamiento de una encuesta sobre la reacción de la demanda turística a la generalizada implantación de aerogeneradores en el occidente asturiano, cuyo daño objetivo al paisaje está siendo llamativo: para sus promotores, si los turistas encuestados se mostraban contrarios, habría que introducir alertas, pues podría quedar dañado económicamente este sector de modo colateral, pero, si eran indiferentes, los parques eólicos serían pragmáticamente perfectos. Está claro que éste no es un planteamiento paisajístico.

Todo el mundo ha podido ver cómo determinada política territorial reciente se llevaba por delante paisajes valiosos sin el menor escrúpulo. E inmediatamente hemos asistido al derrumbamiento de esa política, con el abandono por doquier de sus obras a medio destruir / medio construir con la misma falta de remordimientos. Abandono que las constructoras saben tem- 
poral, al tiempo que preparan nuevos terrenos para futuras oportunidades. Hay incluso en este proceso ciertas licencias llamativas: por ejemplo, es curioso que se hayan alterado tantas fisonomías de lugares y, sin embargo, con frecuencia se utilicen como reclamos turísticos, por los mismos causantes de la transformación, imágenes de cómo eran antes de tales alteraciones. Más concretamente, conozco de primera mano el caso de un hotel de montaña de arquitectura netamente actual, edificado recientemente en un solar que fue abierto tras derruir por completo las interesantes construcciones tradicionales que allí habían resistido el paso del tiempo, que lanza su propaganda electrónica afirmando sin reparos que su edificio procede de fines del siglo XV.

Cierto es que a veces se pretende compensar la deuda de un paisaje perdido aquí con un ecosistema recuperado allá, pero cierto es también que tales arreglos recuerdan aquella anécdota contada por Fígaro en 1834 de un capellán andaluz que debía una peseta a otro catalán sin que encontrara modo de realizar el pago, por lo que el segundo ingenió la siguiente transacción: «Con respecto a la cuenta que de la citada peseta tenemos pendiente, he discurrido que por el presente aviso puede echarla en el cepillo de ánimas de la iglesia de ese pueblo, pues yo ya la he sacado del de ésta a buena cuenta; y en paz» (Larra, 1967). Los paisajes, sin embargo, no son representativos e intercambiables, son más que materializaciones de sistemas abstractos. Son sobre todo individuos geográficos intransferibles. Por eso cada paisaje perdido significa la desaparición de una realidad arraigada y concreta.

Como resultado de lo que venimos escribiendo los paisajes son el lugar y también el lugar del espíritu. Por eso no sólo hay un interior del paisaje sino un paisaje interior. El lado subjetivo del paisaje se acopla al objetivo, se configura a partir de él y lo reconfigura culturalmente, produciendo un salto respecto a la concepción de territorio y zambulléndose en la densidad de los significados, de modo que el paisaje se entiende ya en este momento como un nivel cultural: «fleuves, rochers, forêts, solitudes si chères, / un seul être vous manque, et tout este dépeuplé » (Lamartine, 1963). Cuando se dice que hay que educar geográficamente para que tal educación pise el terreno de la realidad, también se quiere decir que penetra en ese nivel, con todas sus aportaciones, e incluso en la vivencia directa del paisaje, en la experiencia educativa inmediata que no sólo consiste en instruir sino en enseñar a entender y hasta vivir. Como terrestres, entre los objetos, propiedades y sentidos de la Tierra, cuna, sustento, referencia y tumba, entre otras cosas mayores. El aprecio a los paisajes también se puede aprender.

Así que por paisaje debemos entender primero una configuración geográfica, una estructura y una morfología territorial identificada como tal con 
cuerpo, profundidad y volumen, con dinámica y con funcionalidad, con valores objetivos y subjetivos. Un orden material y un objeto de conocimiento para comprenderlo, disfrutarlo, ponderarlo y administrarlo. Sus valores subjetivos constituyen su contenido y, por tanto, son indispensables para conocer sus significados, sus sistemas no sólo naturales, sociales, sino de sentidos, de referencias culturales múltiples, de estilos, vinculaciones, identidades, adscripción, relación y pertenencia. En el caso de la naturaleza damos por supuesto un orden como un jardín a la escala del mundo con sus espacios, pautas, distribuciones, ritmos, escenarios y armonías, del que a veces sólo quedan retazos progresivamente más pequeños y espaciados. La apariencia es parte del paisaje, sólo una parte. Pero lo que genera no es una parte cualquiera.

En su viaje a Cauterets escribía Victor Hugo: «un pastor sueña en estas rocas con el ruido de esta naturaleza tumultuosa». Siempre hay un sueño interpuesto y por ello es inevitable. Sigue Hugo: «un rayo de sol pasa a través de las nubes y hace de cada gota de agua una chispa». También siempre hay un descubridor de la belleza y hay que contar con ella. "La tormenta se acerca. Grandes y sonoras gotas de lluvia caen sobre los árboles y las rocas - prosigue el escritor-. Un rayo. Trueno. Un trueno en estas gargantas ya no es un trueno: es un pistoletazo. Pero un pistoletazo monstruoso que estalla en las nubes, cae en la cima más cercana y rebota de montaña en montaña con un ruido seco, siniestro y formidable». Ahí está la vivencia admirada y sobrecogida. «Es una especie de oscuridad pálida entrecortada por rayos en la que ya no se oyen más que dos rugidos: el torrente que brama sin cesar y el trueno que retumba de vez en cuando. Pensaba en este doble ruido y me decía: el torrente se parece a la rabia y el trueno a la cólera». Aquí aparece el poeta. Pues todo esto es el paisaje con sus mejores ingredientes: lugares, sueños, belleza, fuerza, experiencia, drama y escritura. ¡Ah, y armonía!: «el valle era una urna inmensa en la que el cielo... derramaba la paz de las esferas y el resplandor de las constelaciones», de modo que «estas cosas son más que paisaje», que el paisaje es más que paisaje. Las realidades sensibles — concluye Hugo- nos conmueven, «se produce un espejismo en nuestro interior y tomamos las ideas que nos sugieren para una vida nueva que tienen» (Hugo, s.a.).

$¿$ No hay un punto de individualidad hasta en las mismas cosas? ¿No lo hay en los sitios? Tal calle, tal plaza, determinado tejado, edificio, incluso puerta o balcón, alameda, río, laguna, peña, costa. ¿No es el Teide un gran individuo geográfico reposando sobre la isla de Tenerife? Y en el árbol singular, el gran quejigo, el haya perdida ¿no hay aún más individualidad? El famoso zorro del guadarrameño collado de Marichiva que se acerca dócil a los excursionistas 
¿es cualquier zorro, género y especie, o es él, no intercambiable, el que te recibe en su propiedad con gesto distante? Siempre los lagos han tenido una inquietante personalidad, cada lago la suya. Son como un imán y un temor localizado, dirigen su entorno, mandan en su territorio, le dan foco. En otro polo, nadie negará la individualidad de su pueblo. El pueblo agrupa, concentra, retiene y no sólo por sus utilidades, sino por sus significados. ¿Qué campo no tiene un nombre cuando se penetra en sus recodos, aunque no parezcan significativos al profano? ¿No tienen nombre hasta los espacios del mar, aparentemente iguales $\mathrm{y}$, sin embargo, plagados de referencias concretas para quienes los viven? ¿No los han de multiplicar los vericuetos, las montañas llenas de esquinas y revueltas, de espolones, canales, repisas, fisuras, agujas, pirámides y recuencos? Nada ha sido tan individualizado como las montañas. Tienen nombre, figura, presencia y hasta gesto. Cada montaña es un carácter y una historia, un contenido. No son intercambiables. Son identificables, concretas. Poseen personalidad; o, mejor, les otorgamos identificación, personalidad y nombre. La montaña identificada es un logro cultural, y lo contrario lo contrario. Lo es porque es paisaje y es paisaje porque es una consecución cultural. Cuando se conoce, la Tierra, las cosas, las plantas, los animales, los lugares se revelan siempre con personalidad. Los conjuntos vivientes, por ejemplo la peña, el musgo, la araña, la raíz del arce, el viento, mis pasos, tienen una personalidad compuesta, una forma y una faz propias, suyas y mías, por las que transcurren las vidas, incluso yo mismo que participo del paisaje. El paisaje es así un individuo geográfico preciso, casi orgánico y vivo (o muerto) y las existencias pasan por ellos como los ríos por sus valles. Al haber tal personalidad identificada o concedida, puede haber diálogo o, como decía Unamuno, reciprocidad con el paisaje: hay alma en el paisaje, hay paisaje en el alma.

Por eso el arte y la ciencia se han internado a lo largo de los meridianos y los paralelos en un movimiento cultural entusiasta que abarca todas sus manifestaciones posibles: geografía, exploración, naturalismo, literatura, pintura, música. Han sido sobre todo las miradas viajeras modernas las que lo han visto así, mientras para el labriego, el transportista, el montañés, el arriero, el contrabandista y el peregrino obligado, las asperezas del terreno, del clima o de los lugareños no pasaban de ser meros inconvenientes. Y esas miradas han visto lo evidente; la rueda de la vida en el paisaje. La que gobierna y repite sin cesar el paso de las estaciones, modo fundamental de mostrarse las armonías naturales. La estacionalidad ordena en una rutina paisajes y vidas en recuerdos y sensaciones del repetido rodar de trabajos, tonos y hálitos. No existe más presencia de los paisajes que la expresada a través del modo fundamental 
de repetirse del mundo. La expresión ritmada de lo que se sabe que es fugaz, porfiado y equilibrado. El paisaje es la faz mudable de cada tiempo en sentido circular, de la vuelta de las cosas en que podemos confiar; la reiteración propia del mundo. El modo de reafirmarse periódicamente en sus reglas.

Deseo aquí transmitir unas breves incitaciones paisajísticas a través de lo escrito por algunos viajeros. Para el inmediato, casi doméstico, Guadarrama recojo un texto de Giner de los Ríos, publicado en 1886 —en su conocido artículo titulado Paisaje-, que dice así: «el goce que sentimos al hallarnos en medio del campo, al aire libre, verdaderamente libre» se advierte no sólo en la vista, sino en todos los sentidos, en un estado perceptivo global y en un momento de «representaciones libres, que extiende nuestro goce más allá del horizonte del sentido», incluso produciendo a los observadores, "sobrecogidos de emoción», una intensa sensación de recogimiento (Giner, 1886). En sintonía, confesaba George Sand que retenía su experiencia pirenaica de 1825 como un sueño o un ideal de haber vivido en las montañas sublimes con largos momentos de recogimiento y contemplación, de escucha de la naturaleza y con posesión plena de sí misma (Sand, 1887). Por eso, un gran guía de los Alpes, Gaston Rébuffat, escribía en 1954 que «el guía no escala para él mismo: abre las puertas de sus montañas como el jardinero las verjas de su parque» (Rébuffat, 1982). Del Tíbet, con el Himalaya al fondo, ha contado Tom Longstaff, a mediados del siglo xx, su experiencia del paisaje inmenso: «tan alto se nos aparecía el cielo - escribe- que no pude sustraerme a una curiosa sensación de liberación de la materia, algo así como cuando en sueños se pierde contacto con el suelo y se remonta en el espacio» (Longstaff, s. a.). El sentido de la cadencia de un paisaje está ejemplarmente expresado incluso en lo que no se ve, como en aquella cuarta sinfonía de Sibelius que sugiere el oscuro paisaje invernal finlandés, traduciendo a música escrita un ambiente y permitiendo al oyente volver paisaje lo que escucha con entrega. El viajero, expresado en sentido voluntario y hasta exploratorio, se sumerge en los paisajes. El paisaje es su medio y su objetivo, primero porque lo ve, pero sobre todo porque lo atraviesa acomodándose a sus rugosidades, al aceptarlo como tal y al adecuarse a sus condiciones. De este modo, su travesía es el sentido mismo del viaje. Y no hay mayor adaptación que la requerida por los paisajes fuertes, que imponen condiciones severas, que reclaman toda la atención, como pueden ser los desiertos, las selvas, los glaciares y las montañas. Así, tal vez el entendimiento del interés del paisaje solicita a última hora el espíritu del viajero.

Y, frente a esta afirmación de las armonías, también hay desarmes de los paisajes desazonados por los desasosiegos y las irrupciones de lo vulgar, de lo práctico a ultranza, de lo feo como instrumento. Hay ruinas evidentes, explo- 
siones llamativas y hay también desmoralizaciones sutiles que se aprecian en detalles, cuando los paisajes, por ejemplo, han arrojado la toalla ante lo útil, lo fácil y lo feo. Hay que saber guardarse de las disarmonías, por leves que parezcan, que indican falta de cuidado, practicismos que luego se traducen en peores y peores desconciertos, desalientos, abandonos y deslizamientos. La calidad llama a la calidad como el error llama al error.

Los paisajes que son o eran o que evocan o evocaban lo lejano han rodeado las regiones de los hombres con una bruma persistente. Hasta su asalto geográfico, muy reciente, hasta el generalizado desvelamiento derivado primero de la exploración y ahora de las nuevas técnicas de teledetección, por las brumas sólo transitaban los mitos, el miedo, los forzados, los valientes y los entusiastas. Han sido obstáculos, peligros, áreas estériles, inútiles, fronteras, en oposición a las cuencas fluviales, caminos y labrantíos alrededor del agua o comercios e imperios a través de las aguas.

En suma, queda visto que el paisaje es un conjunto o complejo real en el que la Tierra se configura pedazo a pedazo como un mosaico. Hay paisajes naturales, rurales, urbanos y mixtos, con distintos dominios, mezclas y tendencias. Su tejido es la forma y el rostro del Planeta, su monotonía o multiplicidad; hay paisajes cotidianos, paisajes perdidos en el tiempo y algunos aún escondidos en el espacio. Todo paisaje es un interior y un exterior, un individuo y una familia. Todo paisaje tiene y cuenta una historia, millones de años de las rocas, milenios del clima, siglos de arboledas, campos y ciudades. Quien mira un paisaje y sabe su idioma, lee un pasado acumulado de fuerzas geológicas, cambios climáticos, pasos de estepas y bosques, ríos o lagos, cazadores, ganaderos, agricultores, ejércitos devastadores, reconstrucciones pacientes, quemas de bosques, jardines, economías y sociedades que se fueron o que persisten o que llegan. En la medida que el paisaje es un hecho cultural, necesitará una aproximación cultural. En la medida que es una circunstancia vital, requerirá su vivencia. Es decir, la comprensión del paisaje es un ejercicio intelectual completo, donde, además del indispensable rigor y la necesaria inteligencia, son particularmente apropiadas la sensibilidad y la experiencia directa, saber dialogar con el marco.

Si esto es así, el paisaje es una realidad geográfica y un instrumento de conocimiento y de gestión. Desperdiciarlo es apostar por no conocer, por no discernir, por ir contra la cultura y por no actuar debidamente al perder un instrumento necesario. Por eso hay que proclamar que, en cualquier lugar y en cualquier caso, el paisaje es una clave de entendimiento, de actuación y de conservación en el Planeta. En el ámbito de la naturaleza, cuyo estudio está acomodado a sus avances en ciencias sólidas, probadas y ya afianzadas, el 
planteamiento paisajista no siempre está integrado; en su actuación gestora y protectora frecuentemente no pasa de ser un adorno. Sin embargo, en los dominios naturales el paisaje es una realidad completa, afincada con raíz en el espacio, a la vez tangible y cultural, que concentra todos sus ingredientes y procesos.

Si una ermita está en un cerro, será el conjunto de ambos lo que forma el paisaje, no la ermita por su lado como objeto de arte y el cerro por otro como forma de relieve local. Esto es, el paisaje necesita a ciencias y letras, naturaleza y humanidades conjuntamente, y por eso es más difícil académicamente, además de requerir un método apropiado, centrípeto, no centrífugo, de asociación de conocimientos a su servicio y no al de las especialidades académicas multidisciplinares. Si queremos proteger esa realidad manifestada en forma de paisaje habrá también que operar convergentemente; es decir, si, por un lado, la naturaleza tiene sus normas propias, sus centros de gestión, sus profesionales y sus consejerías y ministerio, incluso sus tendencias, y lo mismo ocurre con los monumentos, estaremos ante una disociación mutua entre los encargados de ecosistemas y especies y los que se ocupan de iglesias, palacios y castillos. No digo que ecosistemas y monumentos no estén bien en lo suyo, claro que lo están; el problema reside en su validez, sólo parcial, para la comprensión completa y la acción integral de una realidad geográfica compuesta. Trataríamos de sacarlos de sus recipientes incomunicados, pero con el empleo del concepto de paisaje tal integración, tal como se presenta en la Tierra, está resuelta.

Del paisaje, que es lo perceptible como agrupación y como significado, no se ocupa casi nadie, o al menos casi nadie con competencia de actuación. Si a esto añadimos que en el paisaje hay un importante lado otorgado por la cultura e incluso subjetivo y que, cuando guardamos uno especialmente valioso, no sólo protegemos su configuración, su estado y su dinámica, sino la posibilidad de mantener su experiencia cualificada o su carácter educativo —más que recurso didáctico-, es posible que desbordemos casi todos los cauces previstos por el uso y por las normas. Si la costumbre persiste, cuando la idea llegue a quien debe llegar hablará inevitablemente de lo que domina y lo que le compete, es decir, lo reconvertirá en el planteamiento establecido, bien de ecosistemas o bien de patrimonio monumental. Y el paisaje quedará de nuevo desvaído o como un ornato o una perspectiva desde un mirador. O incluso como un recurso verbal para una exposición de borrajas, como también se ha planteado en una administración concreta, en actitud más cercana a la resonancia de las palabras que a su contenido. En el paisaje (real o estudiado o gestionado) hay, no obstante, exigencia propia y no ocurre que cada cual vaya 
a su aire y a su asunto. Restablecer en nuestra mirada el sistema que está en la realidad necesita, sin embargo, aparte de concepto, método, objetivo y conocimiento, de cierta insistencia que venza las muchas inercias adquiridas y, sin duda, estamos aprovechando esta ocasión, una vez más, para ello. Y, si todo esto es aplicable a cualquier lugar, la naturaleza es especialmente apta, por su configuración tan normalizada y calcada de la interdependencia de sus ingredientes, para mostrarse con eficiencia desde sus paisajes. Y, en ella, las montañas son más favorables a este tratamiento, no sólo por su gran aparato escénico, sino por su fidelidad al esquema interconectado y morfológico del paisaje. La montaña es formalmente el calco del concepto de paisaje. Únicamente queda, pues, que venzamos rutinas y nos pongamos a ello.

Terminemos con una cita más, ésta de Schopenhauer, recogida también por Marangoni (Marangoni, 1951): «un cuadro es como un rey: hay que esperar a que hable antes de hacerlo nosotros». Sólo debemos cambiar la palabra cuadro por paisaje.

Recibido: 26/07/2010

Aceptado: 23/09/2010

\section{BIBLIOGRAFÍA}

Bacon, F. (1961): Ensayos. Madrid, Aguilar.

Bradbury, R. (1965): Fahrenheit 451. La Habana, Revolución.

Calvino, I. (1994): Las ciudades invisibles. Madrid, Siruela.

Deffontaines, P. (1980): Petit guide du voyageur actif. París, Presses d'Ile de France.

Forner, J. P. (s. a.): Exequias de la lengua castellana. Madrid, Compañía Ibero-Americana de Publicaciones.

García Fernández, J. (1975): Organización del espacio y economía rural en la España atlántica. Madrid, Siglo XxI.

Giner de los Ríos, F. (1886): "Paisaje", La Ilustración artística. Reproducido, entre otros, en Ensayos y cartas, Tezontle, México, FCE, 1965, y en Boletín de la Institución Libre de Enseñanza, 34-35, Madrid, 1999.

Hugo, V. (s. a.): Narraciones de viaje. Alpes y Pirineos. Barcelona, Seix.

Hugo, V. (1990; or. 1856): "Contemplations, livre sixième", en Daniel Fouquet, Yves Stalloni: Textes \& documents sur la nature. Paris, Marketing Ellipses.

Lamartine, A. de (1963): Oeuvres poétiques. París, Gallimard.

Larra, M. J. de (1967): En este país y otros artículos. Madrid, Alianza.

Longstaff, T. (s. a.): Recuerdos de viaje. Del Himalaya al Ártico. Barcelona, Labor. 
Marangoni, M. (1951): Para saber ver. (Cómo se mira una obra de arte). Madrid, Espasa-Calpe.

Nogué, J. (ed.) (2007): La construcción social del paisaje. Madrid, Biblioteca Nueva.

Ortega Cantero, N. (1987): Geografía y cultura. Madrid, Alianza.

Pascal, B. (1958): Pensées. París, Le livre club du libraire.

Pessoa, F. (1996): Máscaras y paradojas. Barcelona, Edhasa.

Prada, E. (2004): El paisaje como archivo del territorio. Madrid, Universidades de la red de Cuadernos de Investigación Urbanística, "Cuadernos de Investigación Urbanística 40".

Prévert, J. (1955): La pluie et le beau temps. París, Gallimard.

Rébuffat, G. (1982): Estrellas y borrascas. Barcelona, R. M.

Sand, G. (1887): Mi hermana Juana. Madrid, El Cosmos.

Saint-Exupéry, A. de (1946): Le Petit Prince. París, Gallimard.

Terán, M. de (1960): "La situación actual de la Geografía y las posibilidades de su futuro": Enciclopedia Labor, vol. IV: El hombre y la Tierra. Barcelona, Labor, pp. XXIII-XXXIX.

Unamuno, M. de (1988): Andanzas y visiones españolas. Madrid, Alianza.

Unwin, T. (1992): El lugar de la Geografía. Madrid, Cátedra.

\section{RESUMEN}

Es preciso enseñar a ver el paisaje desde la geografía y difundirlo. Para ello se cuenta con abundantes recursos propios y con orientaciones renovadoras. Este saber mirar geográfico requiere conceptos, perspectiva y método, que se repasan en este trabajo, con propuestas teóricas y prácticas.

PALABRAS ClaVE: paisaje; geografía; saber ver; marco; experiencia.

\section{Abstract}

We need to teach how to look at the landscape from geography and to spread it. There is a lot of resources and innovative directions. This kind of geographic gaze requires concepts, perspective and method, which reviews in this paper, with both theoretical and practical proposals.

KEY WORDS: landscape; geography; to know to see; framework; experience.

\section{RÉSUMÉ}

Il est nécessaire d'enseigner à voir le paysage depuis la géographie et le diffuser. Pour cela on dispose des ressources propres abondantes et des orientations nouvelles. Ce savoir voir géographique requiert des concepts, de la perspective et de la méthode, qui sont révisés dans cet travail, avec de propositions théoriques et pratiques.

MoTS CLÉs: paysage; géographie; savoir voir; cadre; expérience. 